\title{
The Application of IT Governance Frameworks in Saudi Arabia: An Exploratory Study
}

\author{
Aisha Almaawi \\ University of Jeddah, College of \\ Computer Science and Engineering, \\ Department of Information Systems \\ and Technology, Jeddah, Saudi \\ Arabia
}

\author{
Lama Alsaggaf \\ University of Jeddah, College of \\ Computer Science and Engineering, \\ Department of Information Systems \\ and Technology, Jeddah, Saudi \\ Arabia
}

\author{
Heba Fasihuddin \\ University of Jeddah, College of \\ Computer Science and Engineering, \\ Department of Information Systems \\ and Technology, Jeddah, Saudi \\ Arabia
}

\begin{abstract}
This paper introduces and exploratory study that aims to explore the Information Technology (IT) Governance in Saudi Arabia. The goal is to identify the most commonly used IT Governance frameworks in both government and private sectors in Saudi Arabia. In addition, the study aims to identify the reasons that lead to selecting certain frameworks in both private and government sectors. This study is considered among the first studies that explore IT Governance in Saudi Arabia. IT workers perspectives were collected using an online questionnaire. The results show that IT Governance is still vague in the government sector compared to the private sector. The most used frameworks were identified, and the reasons were also recognized. The study revealed some facts that may lead to future research and investigations.
\end{abstract}

\section{Keywords}

Information Technology, IT, Governance, Government Sector, Private Sector, KSA, Saudi Arabia, vision 2030, COBIT, ITIL, ISO

\section{INTRODUCTION}

Nowadays, various countries around the world are working diligently toward digital transformation. Saudi Arabia is one of the countries that published a determined and clear vision for 2030 [1][2]. Digital transformation of the country's main organizations and informatics is one of the main goals in this vision. Various sectors including education, health and commerce of both private and government sectors, are working to achieve the 2030 vision of the kingdom. This contributes to a serious shift in the quality and speed of services provided to citizens and employees from different sectors including health, education and many others [3]. This is achieved through the well prepared and equipped Information Technology (IT) infrastructure at these sectors.

Despite the benefits that could be achieved with the digital transformation, there are many concerns raised. For instance, the quality of services, the security and privacy of clients' information, the cost of implementing this transformation, and other concerns that cannot be contained in this paper.

To overcome the concerns raised from adopting technologies, Information Technology (IT) Governance is emerged. IT Governance is the processes to ensure an efficient and effective use of IT to enable organizations to achieve their strategic goals [4]. Another definition defines IT Governance as an approach that uses the tools, processes, and methodologies to enable the organizations to align their business and strategic goals with technology (services, programs, infrastructure, etc.). This includes policies that can measure and monitor how systems and control methods are being managed [5].

Hence, the existence of IT Governance within sectors concerned with digital transformation is necessary and imperative. IT Governance framework is a type of framework that defines the ways and methods through which an organization can implement, manage and monitor IT Governance [6]. It provides guidelines and measures to effectively utilize IT resources and processes within an organization [7].

There are many frameworks available for IT Governance. Commonly known and used frameworks, such as COBIT, ISO and ITILL are briefly introduced below [8]. The authors aim to study these three frameworks from several aspects within Saudi different sectors. The goal is to identify the reasons that lead to choose a certain framework, and the advantages of considering it. This explorative study is based on the perspectives of workers in the IT departments in different sectors.

This paper is organized as follow: first a background of IT Governance frameworks is provided in section 2. Next, the methodology of this study is described in section 3. After that, the results are represented in section 4 followed by a discussion in section 5; and finally, the paper is concluded in section 6 .

\section{BACKGROUND}

This section provides an overview of the IT Governance framework that is considered in this study. These frameworks are: COBIT, ISO/IEC 38500 and ITIL.

\subsection{COBIT}

The Control Objectives for Information Technologies (COBIT) is a "trusted" open standard that is increasingly being used by a diverse range of organizations around the world. COBIT framework was created by the ISACA (Information Systems Audit and Control Association) for IT Governance and management [9]. Their latest release of COBIT 2019 builds upon a 20-year legacy of successful governance activities. Figure 1 shows the evolution of this framework over the years. 
1996 Released the first edition of COBIT framework 1998

The second version of COBIT added control to the framework

2000

COBIT's third iteration included Management Guidelines

\section{COBIT 4.0 debuts}

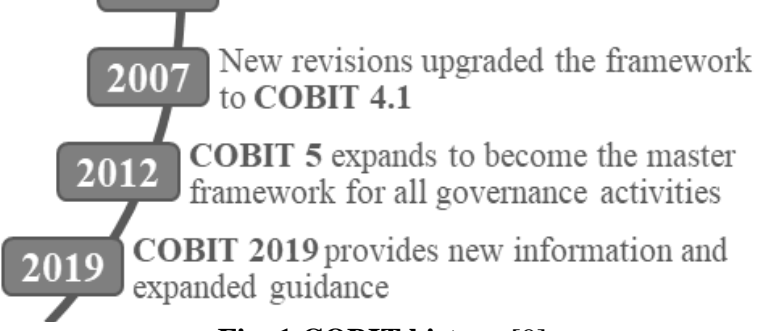

Fig. 1 COBIT history [9]

COBIT is designed to be a supportive tool for managers. COBIT is arguably the most appropriate control framework to help an organization ensures alignment between use of IT and its business goals, as it places emphasis on the business need that is satisfied by each control objective [10]. Figure 2 shows that main principles of COBIT.

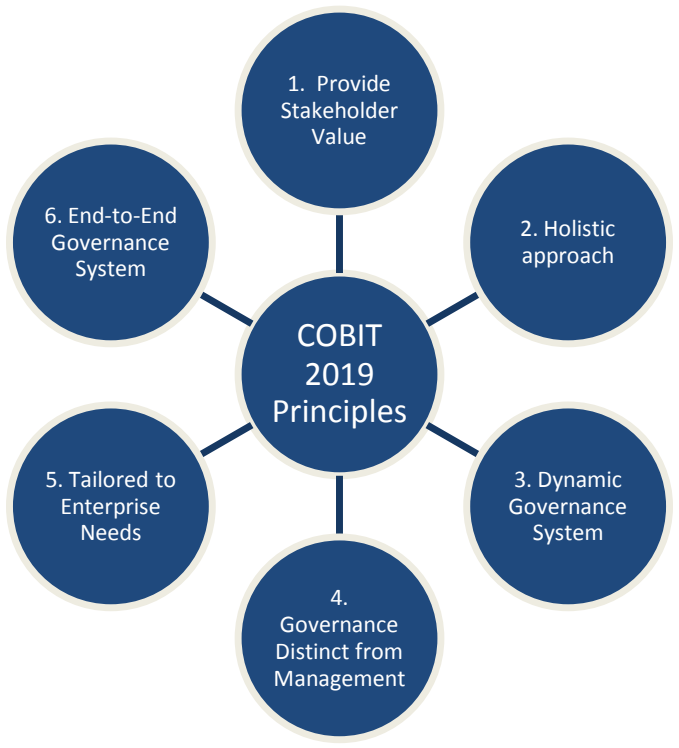

Fig. 2 COBIT principles [9]

\subsection{ISO/IEC 38500}

ISO/IEC 38500 is an international standard published jointly by the International Organization for Standardization (ISO) and the International Electrotechnical Commission (IEC) for Corporate ITG [11]. It provides a framework for effective IT Governance to assist those at the highest level of organizations structure to understand and fulfill their legal, regulatory, and ethical obligations with respect of their organizations' use of IT. It is designed to promote effective, efficient, and acceptable use of IT in organizations by 1) assuring stakeholders confidence in the organization's IT Governance; 2) informing and guiding directors in governing the use of IT in their organization; and 3) providing a basis for objective evaluation of the corporate IT Governance [12].

The ISO/IEC 38500 technical standard was developed by Standards Australia Committee IT-030 and published in January 2005 with the name "AS 8015-2005" (Australian
Standard for Corporate Governance of Information and Communication Technology). Then, shortly before final approval of the standard, the ISO/IEC chose to rename the document to ISO/IEC 38500, and then published its finalized version on June 1 as ISO/IEC 38500:2008 (figure 3) [13].

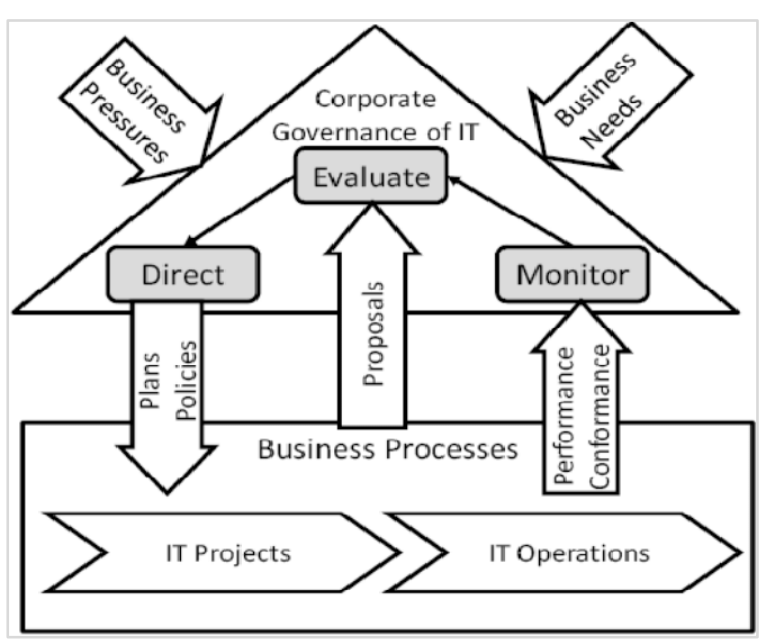

Fig. 3 ISO/IEC 38500:2008 [13]

Later in 2015, ISO published an update of the ISO/IEC 38500:2008 international standard with minor changes and named it ISO/IEC 38500:2015 [14] (see Fig 4).

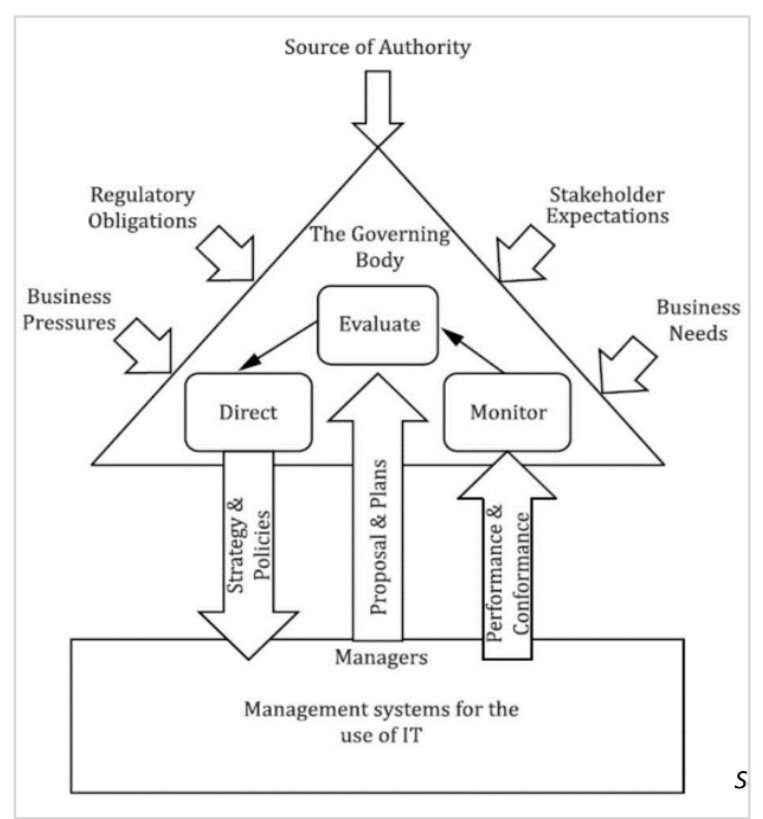

Fig. 4 ISO/IEC 38500:2015 [14]

2.3 ITIL

ITIL is globally recognized as one of the best practice methodologies for IT service management (ITSM). ITIL ensures that organizations' IT services are aligned to the business goals. It provides trusted guidance on how businesses can utilize their IT services in order to support their goals and facilitate their business growth. ITIL is supported by an official range of certifications that provide knowledge of service management best practice and guidance on how to apply this knowledge across the IT service lifecycle. It is structured into five core publications to provide best practice guidance for an integrated approach to IT service management (ITSM) [15][16]. ITIL framework structure is illustrated in (see Fig. 5). 


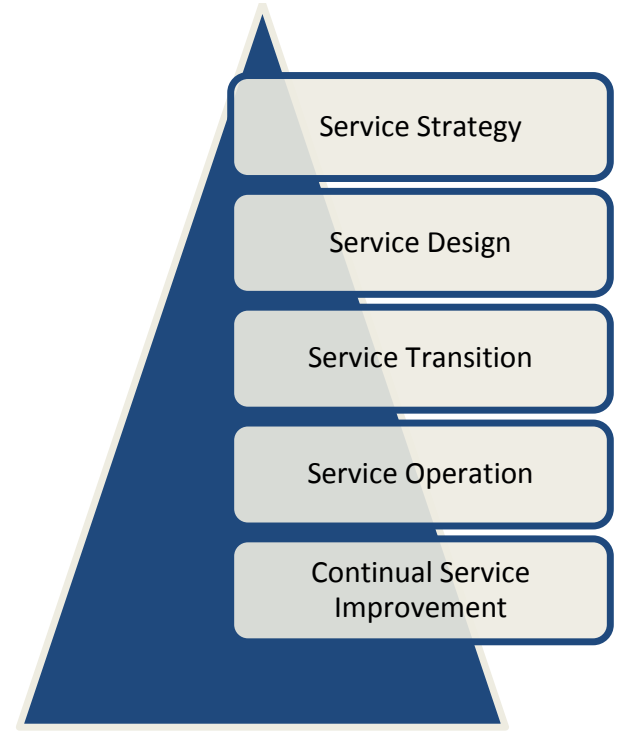

Fig. 5 ITIL structure of the five core publications [15]

ITIL describes processes, procedures, tasks, and checklists which are not organization-specific nor technology-specific, but can be applied by an organization toward strategy, delivering value, and maintaining a minimum level of competency. It allows the organization to establish a baseline from which it can plan, implement, and measure. It is used to demonstrate compliance and to measure improvement.

\section{METHODOLOGY}

As stated earlier in this paper, the aim of this study is to explore the most common IT Governance frameworks in Saudi's various government and private sectors, and the reasons behind choosing these frameworks from the perspectives of IT workers. In order to achieve this goal, a questionnaire was used to collect IT workers thoughts. The questionnaire consists of a group of questions that are revolved around the scope of the study. Quantitative and qualitative data were collected and analyzed using the SPSS statistical tool.

In order to validate the collected data and assure that participants meet the criteria of target sample, the questionnaire asked about the sector the participant is working in as well as the department. The result of any participant who is not working in an IT related department was excluded from the analyzed data. In addition, participants were asked about their level of knowledge about IT Governance, so that the given perspectives can be considered.

In order to specify the most common used IT Governance framework in Saudi Arabia, the questionnaire asked the participants to specify the used frameworks in their organizations. Furthermore, to specify the reasons that lead an organization and decisions makers to select a specific framework, the authors referred to the reasons that were reported in [17] and asked the participants to specify whether these reasons are valid in Saudi Arabia. The specified reasons as listed in [17] are:

1- Obtaining best practices for the quality of IT services that integrate information security standards with business risks.

2- Offering high standards for evaluating information technology.

3- Obtaining an international accreditation for information security and management.

4- Managing services and information security efficiently and effectively.

5- Complying with information systems security and regulations.

6- Security controls for changing conditions and vulnerabilities.

7- Providing credibility.

In addition, the questionnaire allows participants to provide other reasons that might be a cause to select a certain IT Governance framework. Thus, new reasons might be discovered. The results of the collected data and the findings of this study are reported in the following section.

\section{RESULTS}

Data from 30 participants were collected and analyzed using the SPSS statistical analysis tool. Analyzed results showed that $70 \%$ of the participants works in the private sector, whereas $30 \%$ works in the government sector.

Most of the participants work in the private sector and are part of the IT department. They work for different organizations from various sectors including banking, health services, industrial and commercial services and the pharmaceutical sector. Their jobs and positions include Senior Governance Specialist, IT GRC, Information Technology Specialist, System Analyst, IT Technical, Technical Support Engineer, and Network Engineer. It was found that, $69 \%$ of the participants are knowledgeable of IT Governance.

In regard to private sector, it was found that the ISO framework is used by $31 \%$ of the participants, $13 \%$ uses COBIT framework and $31 \%$ for a combination of COBIT and ITIL, $13.8 \%$ uses COBIT with NIST, and $6.9 \%$ for both ITIL and all previously mentioned frameworks. NIST $3.4 \%$, ISO and ITIL $3.4 \%$, and $3.4 \%$ for the combination of COBIT, NEST and ITIL. These figures are illustrated in (figure 6).

Regarding the workers' choice of the framework, they prefer to work with, answers were varied between $48.3 \%$ for COBIT, $24.1 \%$ for IOS, $17.2 \%$ for ITIL, and $6.9 \%$ for NIST (figure 7). More future research and investigations is required in order to clarify these results.

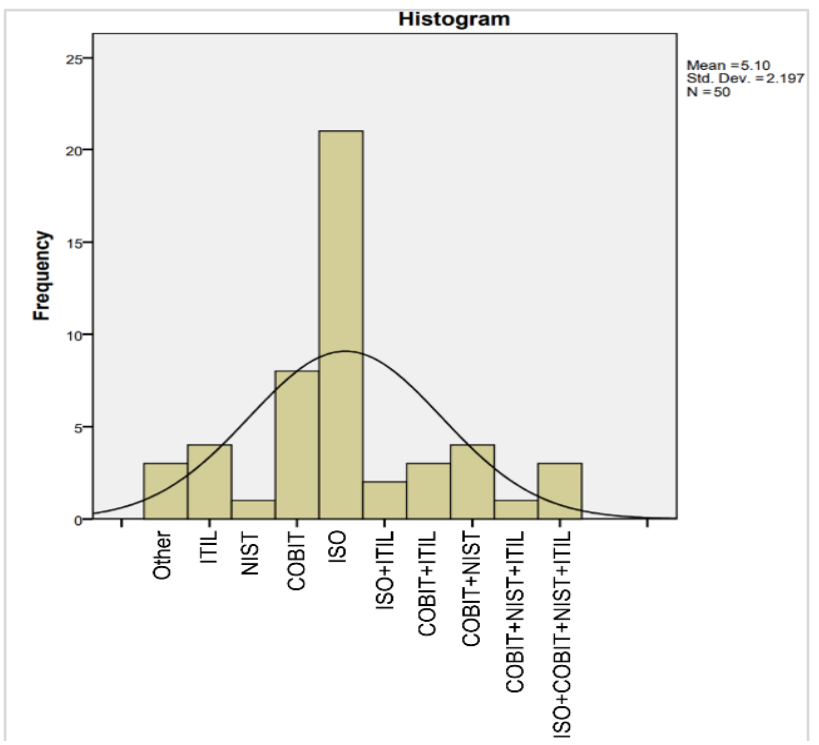

Fig. 6 Use of ITG framework 


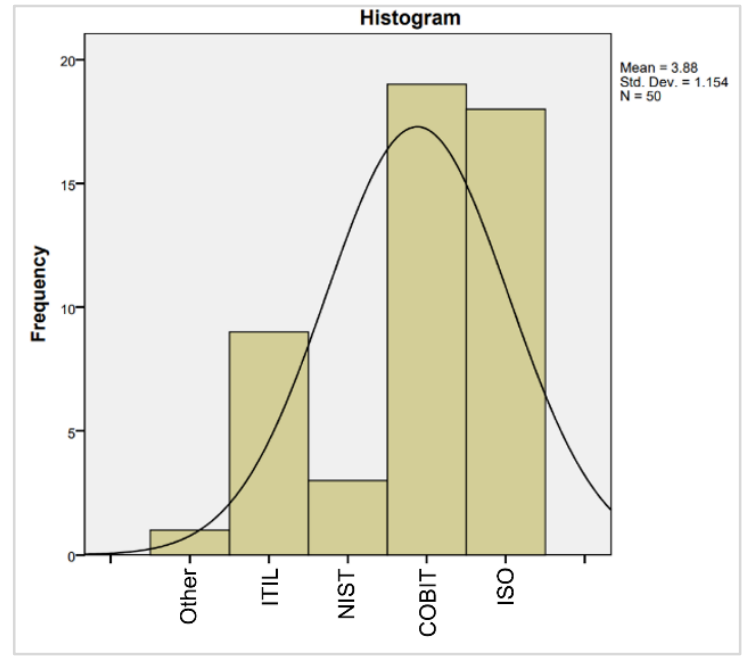

Fig. 7 Preferred IT governance framework

Regarding the reasons for choosing certain frameworks, the participants perspectives were varied about the seven listed reasons in previous the section. $26.92 \%$ agreed that obtaining best practices for the quality of IT services that integrate information security standards with business risks is a reason. $19.23 \%$ agreed with offering high standards for assessing information technology. $17.30 \%$ agreed with obtaining an international accreditation for information security and management. $13.36 \%$ agreed with managing services and information security efficiently and effectively. 9.61\% agreed with complying with information systems security and regulations. $7.69 \%$ agreed with security controls for changing conditions and vulnerabilities, and finally $5.76 \%$ agreed with providing credibility.

In addition to the previous findings, participants provided their thoughts about the reasons of choosing a specific framework in a qualitative form. The data was analyzed, and it was found that the reasons are mostly related to ensuring the quality of provided IT services in integrations with information security standards and business risks. In another word, finding the maximum value from IT through maintaining the balance between achieving benefits, reducing risks' levels, and ensuring the optimal use of resources. In addition, obtaining international certificates and accreditation is another important reason.

In addition, participants provided their opinions on IT operations in relation to IT Governance framework. In regard to COBIT, participants assured that it provides a comprehensive framework that helps in achieving organization's goals that are related to corporate governance and management. Also, participants stressed on the IT role in managing the services and evaluating organization's needs. Another point was for IT role in providing pre-stated plans of communication between the activities of the IT departments with the organizations' managers, shareholders and other parties involved in IT Governance.

Furthermore, other responses revealed that participants would choose the IT Governance framework that offers up-to-date standards, helps in providing technical business solutions, and known with ease of use.

In regard to the government sectors, although the percentage of participants from the government sectors were low comparing to the private sectors, the sample involves workers from various fields, such as education, municipalities and petroleum. Their jobs and positions varied between Information Technology Supervisor, CEO, Technical Support, and Director of Information Technology Department.

In regard to the most used frameworks in governmental sectors, $63.2 \%$ of the participants reported that they use ISO framework in their organizations, whereas $21.1 \%$ use COBIT framework, and the rest which is about $5.3 \%$ use ITIL or a combination of ISO and ITIL.

In regard to the reasons of selecting frameworks in government sectors, the results show that obtaining an international certificate for information security, and obtaining best practices for the quality of IT services that integrate information security standards with business risk were agreed with by $23.33 \%$ of the participants. $20 \%$ agreed with obtaining high standards for IT evaluation, and other.

\section{DISCUSSION}

The main objective of this study is to identify the IT Governance frameworks that are used in government and private sectors in Saudi Arabia along with the reasons that lead organizations to select certain frameworks. The study revealed that there are few frameworks that are commonly used in private sector, as concluded from participants' perspectives, and these frameworks are ISO, COBIT and NIST.

The results of this study indicate that COBIT is a popular framework within the private sector, as $48.3 \%$ of the participants reported that it is used in their organizations. This popularity due to the clarity of COBIT and the well documentation it has, which makes implementation and training a straightforward process.

On the other hand, ISO was found more popular in government sectors. Based on participants' perspectives, most of the government sectors adopt this framework in order to be accredited from such a globally well-known accreditation for the best practices for the quality of IT services. In addition, this result can be explained by the fact that government sectors are usually working on a semi-unified framework for IT Governance. This does not mean that other frameworks are not used in government sectors, as $21 \%$ of the participants reported that COBIT is used in their organizations.

To sum up, based on participants' perspectives, the most important reasons for selecting an IT Governance framework in Saudi Arabia are:

- The ability to adapt the framework within internal operations and regulations.

- The ability to utilize the framework to work toward the Saudi 2030 vision.

- To obtain the best management practices.

- To assure the continuity of quality of service delivery.

- To ensure the availability of the organization's documents.

\section{CONCLUSIONS}

This paper introduces an exploratory study about the state of IT Governance in Saudi Arabia. The study aims to measure the state of implementing IT Governance frameworks in the country in order to lead to more future research and investigation. The goal was to identify the most well- known and commonly used IT Governance frameworks in both 
government and private sectors in Saudi Arabia, and the reasons for selecting certain framework.

A survey using an online questionnaire were conducted to collect IT workers perspectives' regarding IT governance. 30 participants from various government and private sectors occupying different IT positions provided their feedback. The result showed that the ISO framework is the most used in the government sector, while other IT Governance frameworks, namely, ISO, COBIT and NIST are the most used frameworks in the private sector. The other major finding is the fact that IT Governance in Saudi Arabia is still vague to the government sector, as the knowledge of IT governance for IT workers in government sector is limited.

This research is considered among the first to explore IT Governance in both government and private sector in Saudi Arabia. More research and investigation is required to find the challenges and difficulties of implementing IT Governance, advantages and disadvantages of certain frameworks, and even the relation between the nature of the sector and the implemented frameworks.

\section{REFERENCES}

[1] "Saudi Vison 2030," https://vision2030.gov.sa/, accessed Mar. 9. 2020.

[2] M. Al-Ruithe and E. Benkhelifa, "Cloud data governance in-light of the saudi vision 2030 for digital transformation," Proc. IEEE/ACS Int. Conf. Comput. Syst. Appl. AICCSA, vol.2017-Octob, pp.1436-1442, 2018 .

[3] S. Berman and A. Marshall, "The next digital transformation: from an individual-centered to an everyone-to-everyone economy," Strateg. Leadersh., 2014.

[4] H. T. Sihotang, M. Zarlis, S. Efendi, and D. Jollyta, "Evaluation of Maturity Level of Information and Communication Technology (ICT) Governance with CobIT 5.0 Case Study: STMIK Pelita Nusantara Medan," Journal of Physics: Conference Series, vol.1255, no. 1, p.12046, 2019.

[5] M. Spremić, "IT governance mechanisms in managing IT business value," WSEAS Trans. Inf. Sci. Appl., vol.6, no. 6, pp.906-915, 2009.

[6] C. Symons, M. Cecere, G. O. Young, and N. Lambert, "IT Governance Framework - Best Practices," Forrester, pp.1-17, 2005.

[7] W. Van Grembergen, "IT governance and its mechanisms," Proc. Annu. Hawaii Int. Conf. Syst. Sci., vol.8, p.193, 2006.

[8] M. Iskandar and N. A. Mohd Salleh, "IT Governance in Airline Industry: A Multiple Case Study," Int. J. Digit.
Soc., vol.1, no. 4, pp.308-313, 2010.

[9] “COBITofISACA,"https://www.isaca.org/resources/cobi t, accessed Mar. 9. 2020.

[10] G. Ridley, J. Young, and P. Carroll, "COBIT and its Utilization: A framework from the literature," 37th Annual Hawaii International Conference on System Sciences, 2004. Proceedings of the, pp.8-pp, 2004

[11] C. Feltus, "Introducing ISO / IEC 38500: Corporate Governance in ICT," Corp. Gov., 2005.

[12] P. Language and I. Technology, "The Infonomics Letter The Infonomics Letter," no. November, 2012.

[13] "[ISO/IEC 38500:2008] Corporate governance of information technology."

[14] "[ISO/IEC 38500:2015] Information technology Governance of IT for the organization."

[15] "https://en.wikipedia.org/wiki/ITIL." .

[16] B. C. Potgieter, J. H. Batha, and C. Lew, "Evidence that use of the ITIL framework is effective," 18th Annu. Conf. Natl. Advis. Comm. Comput. Qualif., pp.160-167, 2005.

[17] T. C. Kentopp and C. Sciences, "for a Notional Risk Management Framework," no. July, 2017.

\section{AUTHORS PROFILE}

Aisha Almawi, A computer science graduate, IT supervisor with 11 years of experience in the government sector Currently pursuing master's degree in Enterprise Information Technology.

Lama Alsaggaf, A Senior developer with a bachelor's degree of computer science and 11 years of experience in system analysis, design and development. Currently pursuing master's degree in Enterprise Information Technology.

Heba Fasihuddin, Heba Fasihuddin is an Assistant Professor at the department of Information Systems and Technology in the College of Computer Science and Engineering at The University of Jeddah, Saudi Arabia. She received her BSc degree in Computer Science from King Abdulaziz University, Saudi Arabia, in 2004. She also earned a MSc degree with first class honors in Information Technology from the University of Newcastle, Australia, in 2011. She awarded her $\mathrm{PhD}$ degree in Information Technology from the same university in 2015. Her research interests include adaptive and intelligent systems for collaborative open learning, IoT, applied information systems, and healthcare knowledge management. She has published several publications in peerreviewed journals and conference proceedings. 